\title{
The effect of R\&D novelty and openness decision on firms' catch-up performance: Empirical evidence from China
}

\author{
Zhong Yuquan1,a WU Hongru2,b \\ 1Department of Science and Research, Panzhihua University, Sichuan Panzhihua, 617000, China \\ 2School of Economics and Management, Panzhihua University, Sichuan Panzhihua, 617000, China \\ a375998708@qq.com, b1731416695@qq.com
}

Keywords: Technological catch-up; China; Novelty Openness; R\&D; Innovative performance

Abstract: This paper explores the strategic dimensions of $R \& D$ decisions toward novelty and openness in explaining the performance of latecomer firms in a developing economy. A structural equation model of $R \& D$ decision-making is formulated using survey data from 50 Chinese firms. The dimension of R\&D novelty is defined as the degree of technological newness found in firms' $R \& D$ projects, while $R \& D$ openness describes the degree to which technologies are acquired from external sources. Our results indicate that firms' $R \& D$ decisions regarding novelty and openness are associated with demand opportunities, market competition, technological capability, and external networks. Greater R\&D novelty contributes positively to innovative output but does not affect sales growth. Greater R\&D openness contributes positively to sales growth but negatively to innovative output.

\section{Introduction}

Chinese leaders have long placed the development of science and technology at the center of China's modernization plan, regarding it as the key engine for catching up with advanced industrialized countries $^{[1]}$. Over the last two decades, China has been continuously making substantial investments in R\&D. This spending reached a record high of 162 billion US dollars in 2016, accounting for 1.97 percent of China's GDP and making it the second most R\&D-intensive country in the world since $2009^{[2]}$. Such a huge R\&D effort was also made in the hope of transitioning the country's economy from being labor-intensive and export-led to a more sustainable innovation-driven growth model by 2020, as announced in China's 12th Five Year Plan for Science and Technology Development.

In this economic transitional period, Chinese firms, similar to their East Asian newly industrialized economy (NIE) counterparts in the peak of their catch-up period, face a "strategic dilemma". This dilemma is whether they should try to become innovation leaders, relying on in-house $R \& D$, or continue their low-cost, imitation-based competitive strategies ${ }^{[3]}$. This is particularly relevant for some of China's largest firms (e.g., Huawei, Lenovo, and PetroChina) and is increasingly important for many others that are approaching multinational stages. Given China's substantial investment in technology and innovation, it is important to understand how firms are making their $R \& D$ decisions to catch up and reduce the technological gap with the industrial leaders.

Previous research has well documented the processes of technological capability building by NIE latecomers. One view rooted in the product life-cycle theory is that latecomers improve their 
technological capability following the technological trajectory of the developed country firms by assimilating and adapting relatively obsolete technology ${ }^{[4]}$. Latecomers should initially focus on developing production capability through licensing or joint ventures and then move on to building up independent technological capability in stages ${ }^{[5]}$. An alternative view suggests, on the contrary, that the constraints on an innovation pattern are lifted by technological paradigm shifts ${ }^{[6]}$. This type of 'window of opportunity' allows latecomers to catch up, as all industry players are new to the emerging paradigm. Latecomers can omit some parts of the trajectory or even forge novel pathways, bypassing older technology to catch up with advanced countries ${ }^{[7]}$.

Latecomer transition, however, is not a simple dichotomy between catch-up and leadership strategy, as technological development and innovation are not mutually exclusive options. R\&D investment is not a result of catching up but an important input to enable $\mathrm{it}^{[8]}$. Considerable R\&D is required for firms to achieve radical innovation and alter the patterns of competition. All NIEs have spent a substantial amount on R\&D during their catch-up process ${ }^{[9]}$. However, relatively little is known about the strategic dimensions of latecomer firms' R\&D decisions and the consequential innovation performance in their catch-up process.

2. Theoretical background and hypothesis development

\subsection{The novelty and openness dimensions of R\&D decisions}

The central concern of the literature on adaptive search behaviors is the relationship between the exploration of new vs. exploitation of existing technological capabilities in ensuring firms' competitiveness and the association of different types of learning and innovation ${ }^{[10]}$. Exploitation is described as local searches that locally address 'problems' using knowledge that is closely related to the pre-existing knowledge base of a firm ${ }^{[11]}$. Exploration is characterized as exploratory or distant searches that involve a deliberate effort to depart from present organizational routines and knowledge bases $^{[12]}$. Due to the path-dependent nature of technological innovation, firms need to combine these two search activities. Exploration without exploitation is likely to suffer from the high costs of experimentation and high rates of failure because of the inherent risks and uncertainties. Conversely, exploitation without exploration is likely to be trapped in suboptimal equilibriums due to core rigidities or competency traps ${ }^{[13]}$. Both activities are essential but compete for the same resources. As a result, achieving an optimum balance between the two to combine internal and external knowledge is a primary requirement for making R\&D decisions on search behaviors $^{[14]}$. More importantly, the exploitation and exploration framework indicates that the key difference between the two is the degree to which search behaviors involve the development of new knowledge and sources of such knowledge creation.

The other strategic dimension, R\&D openness, is related to the sources of knowledge creation. Firms need to choose the extent of openness these exploitation and exploration search behaviors should incorporate, i.e., relying mainly on internal R\&D efforts (internalization) or searching for external technology (externalization), to explore and exploit technology innovation. R\&D openness can be seen as the extent to which technologies are acquired from external sources. These strategies cover a mixture of in-house $\mathrm{R} \& \mathrm{D}$, strategic alliances, licensing of technologies, and other approaches. The transaction cost perspective has emphasized the costs related to these external sourcing options, such as organizational coordination, partner selection, risks of imitation, and knowledge leakage ${ }^{[15]}$.

2.2. Dimensions of R\&D decisions toward novelty and openness within catch-up strategy

$R \& D$ search behavior is induced by technological opportunities. Opportunities in the form of knowledge sources are characterized by complementarities between sources that are internal and external to the organization. Together with opportunity conditions, three other factors 
(appropriability conditions, degrees of cumulativeness of technological knowledge, and characteristics of the relevant knowledgebase) are part of the technological regimes that define patterns of R\&D behaviors ${ }^{[16]}$.

Demand opportunity reflects the potential for market demand to induce technological innovation. When market demand is diversified and dominant design does not occur, there will be more demand opportunity for late comers to catch up with less R\&D investment ${ }^{[17]}$. One approach is the use of technological improvement based on imitation to satisfy markets with less demanding customers at a price discount ${ }^{[18]}$. Another is OEM based on importing mature technology to acquire low-cost profits from exportation ${ }^{[19]}$. Otherwise, late comers need to invest more to develop new technological functions based on applied and basic research to avoid a price war under conditions characterized by less variety of demand, high performance preferences, and difficulties in exporting to advanced markets. Accordingly, it is proposed that less demand opportunity with less variety in demand, high price preferences, and strong barriers to exportation require more investment to gain R\&D novelty. Additionally, in-house R\&D will play a more critical role than external technological acquisition under conditions of less demand opportunity when a mature value network sets a high entry threshold ${ }^{[20]}$. Accordingly,

H1.1. Less demand opportunity leads to R\&D decisions oriented towards greater novelty.

H1.2. Less demand opportunity leads to R\&D decisions oriented towards lower openness.

Market competition represents the potential of competition, including imitation from late comers, to trigger technological innovation. High levels of market competition with rapid technological obsolescence and easy product substitution trigger more investment into applied and basic research to fill the competitive gap due to the loss of low labor costs ${ }^{[21]}$. At the same time, greater market competition causes a strong requirement for rapid innovation and calls for breaking down the boundaries of $R \& D$ organizations and making use of technological diffusion from other related industries ${ }^{[22]}$. Hence,

H2.1. Greater market competition leads to R\&D decisions oriented towards greater novelty.

H2.2. Greater market competition leads to R\&D decisions oriented towards greater openness.

Technological capability reflects both the status quo of technological innovation ${ }^{[23]}$ and opportunities for technological innovation in the future ${ }^{[24]}$. Technological capability plays a fundamentally positive role in the transition from imitation to innovation ${ }^{[25]}$ and encourages the development of novel R\&D while approaching the international frontier ${ }^{[26]}$. The positive effect of technological capability on R\&D novelty is based on two perspectives. First, the accumulation of technological capability is path-dependent. Greater technological capability means an accumulation of technological knowledge and management routines, which creates promising conditions for further innovation. Second, existing technological capabilities contribute less to the innovations that are destroying current technological competencies. However, latecomers can only seize technology windows of competence destruction if they possess sufficient technological capability. Technological capability has a positive effect on R\&D openness, considering that late comers with high levels of technological capabilities are inclined to use more in-house R\&D to acquire original innovations ${ }^{[27]}$. Late comers are forced to use external technologies in earlier stages of catch-up because they are unable to initiate original innovation. However, they will endeavor to increasingly rely on their own R\&D efforts to escape being 'locked-in' with technological suppliers as they build ever greater technological capabilities. Therefore,

H3.1. Higher technological capability leads to R\&D decisions oriented towards greater novelty.

H3.2. Higher technological capability leads to R\&D decisions oriented towards less openness. 
Net working provides the possibility for firms to work in a collaborative mode to acquire external technologies and knowledge rather than relying on firms' isolated efforts to innovate. Although some researchers consider technological learning to be an aspect of technological capability $^{[28]}$, these concepts are treated separately in this study because technological learning with linkages to external knowledge resources plays an important role in both technological capability building and technological innovation during catch-up ${ }^{[29]}$. Well organized external networks can contribute positively to R\&D novelty when considering spill-overs that help firms build risk awareness and avoid technological problems that can not or would be costly to solve internally ${ }^{[30]}$. NIE latecomers' experience also shows that external networks can positively lead to R\&D openness, as more investment is directed to various external acquisitions of technology ${ }^{[31]}$. We therefore expect,

H4.1. A wider external network leads to R\&D decisions oriented towards greater novelty.

H4.2. A wider external network leads to R\&D decisions oriented towards greater levels of openness.

2.3. R\&D novelty and openness and firms' innovative performance

Greater levels of R\&D novelty can create more new knowledge, which in turn creates more opportunities to generate more innovative output, such as IPR and new products. However, greater levels of $\mathrm{R} \& \mathrm{D}$ novelty from wider technology categories of new knowledge may increase communication and organization costs when the existing networks of relation- ships begin to span the internal and external boundaries of the organization ${ }^{[32]}$. The stability and reliability of the organization may also decrease ${ }^{[33]}$. Firms might have to invest more time and resources to cope with the increasing complexity of the $R \& D$ projects. As a result, they may experience delays in the launching of target markets, thus hindering scale expansion and sales growth. This suggests that,

H5.1. R\&D decisions oriented towards greater novelty lead to more innovative output.

H5.2. R\&D decisions oriented towards greater novelty lead to slower sales growth.

We expect that greater R\&D openness, with more external technological acquisitions, reduces opportunities to acquire external knowledge, such as IPR and new product development. A survey of Taiwanese firms demonstrated that technology out-sourcing in the form of inward licensing does not contribute to innovation performance ${ }^{[34]}$. However, more external technological acquisition can reduce the time to advance the firm's technological position by assimilating technological developments from benchmarking competitors ${ }^{[35]}$. Furthermore, it reduces the time required to launch innovations relative to internal $R \& D$. The Japanese experience shows that external technological acquisition helps firms to enhance sales in the US market ${ }^{[36]}$. We therefore expect,

H6.1. R\&D decisions oriented towards greater openness lead to less innovative output.

H6.2. R\&D decisions oriented towards greater openness lead to quicker sales growth.

3. Research method

\subsection{Measures}

\subsubsection{R\&D novelty}

We use a different categorization of R\&D projects, including pure science, basic research, applied research, exploratory development, and advanced development ${ }^{[37]}$.

\subsubsection{R\&D openness}

Methods of technological development or acquisition, including in-house R\&D, collaborative $\mathrm{R} \& \mathrm{D}$, technology purchasing, and technology licensing ${ }^{[38]}$, are used as an indicator of $\mathrm{R} \& \mathrm{D}$ organization to calculate the degree of R\&D openness. 


\subsection{Performance}

\subsubsection{Innovative output}

To capture the characteristics of performance during the catch-up process, we measured the innovative output by the share of turnover from new products and the quantity of IPR (the applications for invention patents and utility models).

\subsubsection{Sales growth}

Firms' growth is measured by the sales growth during the last year.

\subsection{Conditions}

\subsubsection{Demand opportunity}

Demand opportunity is measured by the variety of demands, demand preferences, and export opportunities.

\subsubsection{Market competition}

Market competition is measured by the rate of technological obsolescence and ease of product substitution.

\subsubsection{Technological capability}

The current technological capability of a firm is measured by the level of competence and the development stage for technological behavior. The future technological capability of a firm is measured by the level of awareness of threats and opportunities in a number of stages.

\subsubsection{External network}

The external network is measured by various institutional arrangements or sources of technological learning, including foreign direct investment, joint ventures, licensing, OEM, ODM, contracts, and technological alliances.

\subsection{Sample and data collection}

The variables and indicators were obtained from the literature, and some had not yet been validated. The questionnaire was sent to the R\&D managers of Chinese firms in industrial parks in Zhejiang, Jiangsu, Shandong and Sichuan. The sample consists of firms that have implemented a product or process innovation within the last three years, reflecting the OECD definition of an innovative firm. The survey was initiated in February 2016 and completed in March 2016.We received 65 responses, of which 50 (or $76.9 \%$ ) were valid.

4. Analysis of the structural equation model

4.1. Measurement validation

We used such methods as factor analysis and the coefficient of variation to validate our framework. The reliability of variables was assessed. The results suggested that the model adequately fits the data and that the testing of the structural model was appropriate.

4.2. Calculation of novelty and openness in $R \& D$ decisions 
Tables1 and 2 below show the results for the calculation of these two variables.

Table1 AHP result of R\&D novelty

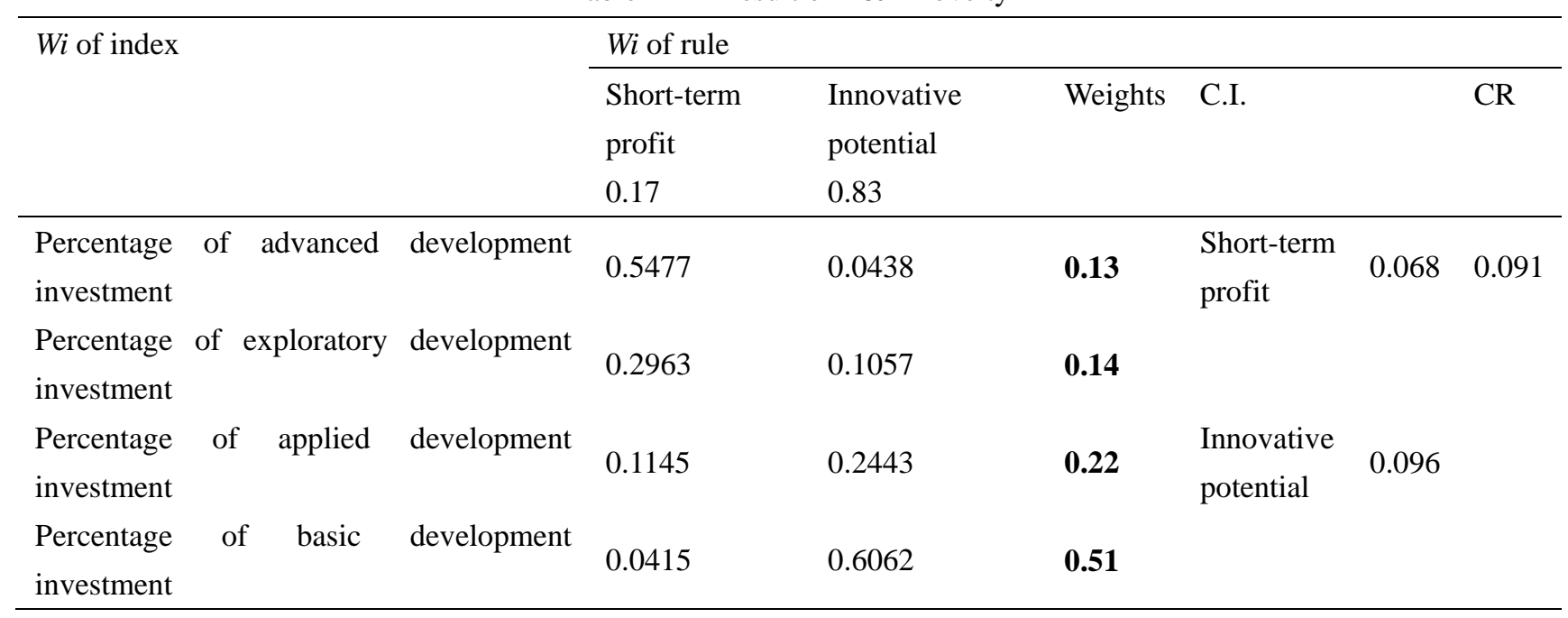

Table2 AHP result of R\&D openness

\begin{tabular}{|c|c|c|c|c|c|c|}
\hline \multirow[t]{4}{*}{ Wi of index } & \multicolumn{6}{|l|}{ Wi of rule } \\
\hline & \multirow{3}{*}{$\begin{array}{l}\text { Innovation } \\
\text { speed } \\
0.83\end{array}$} & \multirow{3}{*}{$\begin{array}{l}\text { IPR } \\
0.17\end{array}$} & \multirow[t]{3}{*}{ Weights } & \multirow[t]{3}{*}{ C.I. } & & \multirow[t]{3}{*}{ CR } \\
\hline & & & & & & \\
\hline & & & & & & \\
\hline Percentage of in-house R\&D investment & 0.0420 & 0.5804 & 0.13 & $\begin{array}{l}\text { Innovation } \\
\text { speed }\end{array}$ & 0.070 & 0.074 \\
\hline $\begin{array}{l}\text { Percentage of collaborative } \quad \mathrm{R} \& \mathrm{D} \\
\text { investment }\end{array}$ & 0.1210 & 0.2846 & 0.15 & & & \\
\hline $\begin{array}{l}\text { Percentage of technology purchasing } \\
\text { investment }\end{array}$ & 0.3128 & 0.0842 & 0.27 & IPR & 0.080 & \\
\hline $\begin{array}{l}\text { Percentage of technology licensing } \\
\text { investment }\end{array}$ & 0.5242 & 0.0508 & 0.45 & & & \\
\hline
\end{tabular}

4.3. Model testing and estimation

The estimation of the model variances of error for the single-indicator variables was accomplished with preinstalled values. The overall fit of the model was satisfactory.

\section{Results}

Of the twelve hypotheses tested, four were rejected because their estimates were not significant. Hypothesis 1.1 is supported, but hypothesis 1.2 is rejected. Hypothesis 2.1 is supported, but hypothesis 2.2 is rejected. Hypothesis 3.1 and 3.2 are supported. Hypothesis 4.1 is supported, but hypothesis 4.2 is rejected. Hypothesis 5.1 is supported, but hypothesis 5.2 is rejected. Hypothesis 6.1 and 6.2 are supported.

6. Discussion and conclusion

In this study, we explored the characteristics of R\&D decisions during technology catch-up using a structural equation model with survey data collected from local companies in China. Two strategic dimensions of R\&D decisions, novelty and openness, were studied to explain latecomers' innovation performance. First, 7 high levels of R\&D novelty, with investment in new knowledge creation, contribute positively to innovative output and sales growth. Second, greater R\&D openness, with greater investments in external technology acquisitions, contributes positively to sales growth but negatively to innovative output, as expected. R\&D novelty and openness are in turn affected by a number of factors. R\&D novelty is positively affected by a firm's market 
competition, technological capabilities, external networks, and reduced demand opportunities. Structurally balanced R\&D decisions on both dimensions of novelty and openness are critical for achieving good catch-up performance. Starting from the specified conditions of innovation, both short-and long-run innovation objectives should be considered in R\&D decision-making.

Acknowledgment

This project was founded by the science and technology department of Sichuan province (No.2015ZR0081)

\section{References}

[1] Bin, G.. Technology acquisition channels and industry performance: an industry-level analysis of Chinese large- and medium-size manufacturing enterprises. Research Policy, 37, (2008), 194209.

[2] OECD, 2016. OECD Science Technology and Industry Outlook 2016. OECD, Paris.

[3] Hobday, M., Rush, H., Bessant, J.. Approaching the innovation frontier in Korea: the transition phase to leadership. Research Policy, 33, (2004), 1433-1457.

[4] Kim, L.. Imitation to Innovation: the Dynamics of Korea's Technological Learning. Harvard Business Press, Boston, Mass, 1997.

[5] Kim, L.,. Stages of development of industrial technology in a developing country: a model. Research Policy, 9, (1980), 254-277.

[6] Perez, C., Soete, L.. Catching up in technology: entry barriers and windows of opportunity. In: Dosi, et al. (Eds.), Technical Change and Economic Theory. Francis Pinter, London, 1988, pp. 458479.

[7] Lee, K., Lim, C.. Technological regimes, catching-up and leapfrogging: findings from the Korean industries. Research Policy, 30, (2001), 459-483.

[8] $\mathrm{Mu}, \mathrm{Q}$., Lee, K.. Knowledge diffusion, market segmentation and technological catch-up: the case of the telecommunication industry in China. Research Policy, 34, (2005), 759-783.

[9] Gill, I.S., Kharas, H.J., Bhattasali, D.. An East Asian Renaissance: Ideas for Economic Growth. World Bank, Washington, DC, 2007.

[10] March, J.G.. Exploration and exploitation in organizational learning. Organization Science, 2, (1991), 71-87.

[11] Ahuja, G., Morris Lampert, C.. Entrepreneurship in the large corporation: a longitudinal study of how established firms create breakthrough inventions. Strategic Management Journal, 22, (2001), 521-543.

[12] Katila, R., Ahuja, G.. Something old, something new: a longitudinal study of search behavior and new product introduction. Academy of Management Journal, 45, (2002), 1183-1194.

[13] Gilsing, V.A., Duysters, G.. Understanding novelty creation in exploration networks-structural and relational embeddedness jointly considered. Technovation, 28, (2008), 693-708.

[14] Bauer, M., Leker, J.. Exploration and exploitation in product and process innovation in the chemical industry. R\&D Management, 43, (2013), 196-212.

[15] Robertson, T. S., Gatignon, H.. Technology development mode: a transaction cost conceptualization. Strategic Management Journal, 19, (1998), 515-531.

[16] Cohen, W.M., Levinthal, D.A.. Absorptive capacity: a new perspective on learning and innovation. Administrative Science Quarterly, 35, (1990), 128-152.

[17] Breschi, S., Malerba, F., Orsenigo, L.. Technological regimes and Schumpeterian patterns of innovation. The Economic Journal, 110, (2000), 388-410.

[18] Murmann, J.P., Frenken, K.. Toward a systematic framework for research on dominant designs, technological innovations, and industrial change. Research Policy, 35, (2006), 925-952. 
[19] Hobday, M.. East Asian latecomer firms: learning the technology of electronics. World development, 23, (1995), 1171-1193.

[20] Christensen, J. F.. Asset profiles for technological innovation. Research Policy, 24, (1995), 727-745.

[21] Tang, J.. Competition and innovation behavior. Research Policy, 35, (2006), 68-82.

[22] Park, K. H., Lee, K.. Linking the technological regime to the technological catch-up: analyzing Korea and Taiwan using the US patent data. Industrial and Corporate Change, 15, (2006), 715-753.

[23] Dosi, G.. Sources, procedures, and microeconomic effects of innovation. Journal of economic literature, 26, (1988), 1120-1171.

[24] Malerba, F., Orsenigo, L.. Schumpeterian patterns of innovation are technology- specific. Research Policy, 25, (1996), 451-478.

[25] Figueiredo, P. N.. Does technological learning pay off? Inter-firm differences in technological capability-accumulation paths and operational performance improvement. Research Policy, 31, (2002), 73-94.

[26] Chudnovsky, D., López, A., Pupato, G.. Innovation and productivity in developing countries: a study of Argentine manufacturing firms' behavior (1992-2001). Research Policy, 35, (2006), 266288.

[27] Hung, S.W., Tang, R.H.. Factors affecting the choice of technology acquisition mode: An empirical analysis of the electronic firms of Japan, Korea and Taiwan. Technovation, 28, (2008), 551-563.

[28] Hernández-Espallardo, M., Sánchez-Pérez, M., Segovia-López, C.. Exploitation and exploration-based innovations: the role of knowledge in inter-firm relationships with distributors. Technovation, 31, (2011), 203-215.

[29] Kim, L.. Building technological capability for industrialization: analytical frameworks and Korea's experience. Industrial and Corporate Change, 8, (1999), 111-136.

[30] Liu, X., Buck, T.. Innovation performance and channels for international technology spillovers: evidence from Chinese high-tech industries. Research Policy, 36, (2007), 355-366.

[31] Cho, H. D., Lee, J. K.. The developmental path of networking capability of catch- up players in Korea's semiconductor industry. R\&D Management, 33, (2003), 411-423.

[32] Henderson, R.M., Clark, K. B.. Architectural innovation: the reconfiguration of existing product technologies and the failure of established firms. Administrative Science Quarterly, 35, (1990), 9-30.

[33] Martin, X., Mitchell, W.. The influence of local search and performance heuristics on new design introduction in a new product market. Research Policy, 26, (1998), 753-771.

[34] Tsai, K. H., Wang, J. C.. External technology sourcing and innovation performance in LMT sectors: an analysis based on the Taiwanese Technological Innovation Survey. Research Policy, 38, (2009), 518-526.

[35] Stuart, T. E., Podolny, J. M.. Local search and the evolution of technological capabilities. Strategic Management Journal, 17, (1996), 21-38.

[36] Mansfield, E.. The speed and cost of industrial innovation in Japan and the United States: external vs. internal technology. Management Science, 34, (1988), 1157-1168.

[37] Amsden, A. H., Tschang, F. T.. A new approach to assessing the technological complexity of different categories of R\&D (with examples from Singapore). Research Policy, 32, (2003), 553572.

[38] Bercovitz, J. E., Feldman, M. P.. Fishing upstream: firm innovation strategy and university research alliances. Research Policy, 36, (2007), 930-948. 